\title{
ESTIMATING FORMWORK STRIKING TIME FOR CONCRETE MIXES
}

\author{
F. 0. Okafor ${ }^{1}$ and D. E. Ewa ${ }^{2}$ \\ 1. DEPARTMENT OF CiVIL ENGINEERING, UNIVERSITY OF NigERIA NSUKKA, NIGERIA. \\ 2, DEPARTMENT OF CiVIL ENGINEERING, CROSS RIVER UNIVERSITY OF TECHNOLOGY, CALABAR, NIGERIA. \\ Email addresses: 1 fidelis.okafor@unn.edu.ng, 2 desmondewa4sky@gmail.com
}

\begin{abstract}
In this study, we estimated the time for strength development in concrete cured up to 56 days. Water-cement ratios adopted range from 0.44-0.57. Nonlinear regression analysis performed on each experimental data set produced Strength-Age (S-A) curves from which Duration-Strength (D-S) models were deduced to estimate approximate time in hours for a particular strength development. A quick reference table for soffit formwork striking time and removal of props was produced. The time to attain the characteristic strengths for C20, C25, C30 and, C35 concrete were 247.04 hours (10.3 days), 285.57 hours (11.90 days), 484.54 hours (20.20 days), 481.58 hours (20.10 days) and, 267.72 hours (11.16 days), 338.74 hours (14.11 days), 560.67 hours (23.36 days), 482.49 hours (20.10 days) for medium and high slump range respectively. Faster construction scheduling operations can be achieved by using lower water-cement ratios and higher grades of concrete.
\end{abstract}

Keywords: Concrete, formwork, compressive strength, water-cement ratio, time.

\section{INTRODUCTION}

Formwork striking time play a major role in construction sequencing and scheduling. Project managers are interested in crashing activities along the critical path in order to meet deadlines, and hence, save time and money. Knowledge of when formwork should be struck off given a particular concrete mix or grade is an invaluable tool to the site management team. [11] specifies various grades of concrete for structural purpose and general construction to include: C20, C25 and C30 at different water cement ratios. The time to attain a particular strength of interest should differ from grade to grade, given the effect of water-cement ratio and workability.

The minimum strength criteria for striking formwork to concrete members as recommended by [9] is shown in Table 1 . The minimum formwork striking time requirement as stated by [8] is also summarized in Table 2.

Table 2 requires that the curing temperature should not be less than $16^{\circ} \mathrm{C}$. With a shorter duration, a minimum of $10 \mathrm{~N} / \mathrm{mm}^{2}$ has been proposed for slabs and beams.

Ref [15] suggested models for minimum period for striking formwork based on the surface temperature of the concrete as shown in Table 3.

In Table $3, t$ is the surface temperature valid between $0^{\circ} \mathrm{C}-25^{\circ} \mathrm{C}$ and the surface of the temperature of the concrete is not obtainable, the air temperature (ambient) may be used.

Table 1: Minimum strength for striking formwork (BS8110)

\begin{tabular}{ll} 
Member & $\begin{array}{l}\text { Minimum Strength } \\
\left(\mathrm{N} / \mathrm{mm}^{2}\right)\end{array}$ \\
\hline $\begin{array}{l}\text { Members in compression, } \\
\text { e.g., columns, to protect } \\
\text { against frost damage }\end{array}$ & 5 \\
$\begin{array}{l}\text { The minimum strength for } \\
\text { member in flexure should } \\
\text { be }\end{array}$ & $\begin{array}{l}\text { which it will be subjected to } \\
\text { whichever is greater, } \\
\text { provided striking at that } \\
\text { time will not result in } \\
\text { unacceptable deflection". }\end{array}$ \\
\hline
\end{tabular}

Table 2: Minimum duration requirement for striking formwork (BS800-2.2:1990)

\begin{tabular}{ll}
\hline Member /formwork & Minimum time \\
\hline Vertical formwork & \\
(Compression members, 12 hours \\
e.g., Columns, walls, etc.) \\
$\begin{array}{l}\text { Soffit formwork (slabs, } 4 \text { days or } 96 \text { hours. } \\
\text { beams, etc.) }\end{array}$ \\
\hline
\end{tabular}


Table 3: Formwork striking model ( $L+C$ Consulting)

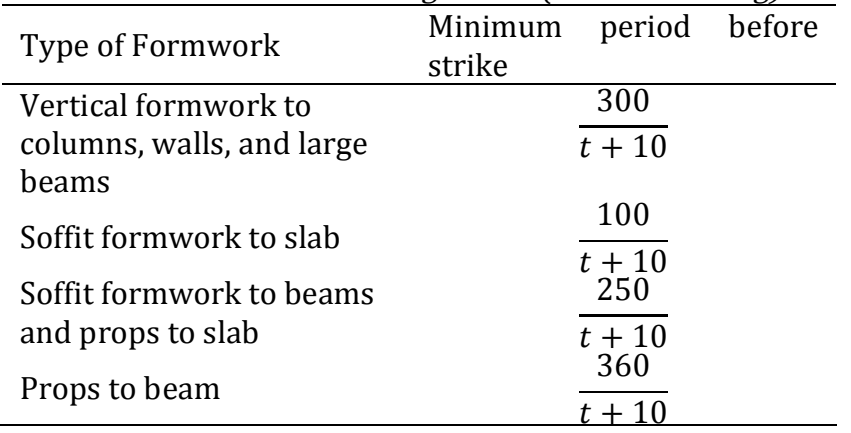

From Table 3, if the surface temperature of concrete or ambient $t$ temperature is $20^{\circ} \mathrm{C}$, the time to strike vertical formwork to columns, walls, and large beams is 10hours. This duration is reduced to 8.57 hours with increase in temperature to $25^{\circ} \mathrm{C}$. These durations are relatively shorter compared to the recommendation of [8].

Temperature Matched Curing method was used by [10] to determine the time to remove formwork for concrete containing ground granulated blast-furnace slag (ggbs). The study reported 4-6.5-day period to satisfy strength requirement for striking formwork for concrete containing up to $70 \%$ ground granulated blast furnace slag.

To avoid damage to vertical members due to frost, [14] suggested a minimum strength of $2 \mathrm{~N} / \mathrm{mm}^{2}$ to be attained for vertical formwork removal. This is based on the assumption that the in-situ concrete is cured under normal conditions [12]. Factors which affects formwork striking time includes, formwork design, workmanship, in-situ concrete placement, concrete grade, mean air temperature, concrete placing temperature type of formwork and section dimensions [10], [12]. With the strength criteria, the engineer could predict the time a structural concrete member will attain the requirement for striking formwork.

This paper presents results of strength versus concrete age in form of charts for different grades of concrete made from crushed aggregate. Non-linear regression analysis using MS Excel 2016 Software performed on the Strength-Age (S-A) relations gave models from which the time for striking soffit formwork, removal of props to slabs and beams for a given mixture-specific concrete grade can be estimated. A knowledge of the time for accommodation of construction loads will make scheduling operations proceed in a faster pace, saving time and money.

\section{MATERIALS AND METHODS}

Ordinary Portland cement Type-I, class 32.5 manufactured by the UNITED CEMENT COMPANY OF NIGERIA, UNICEM was used for the study. The plant producing UNICEM is located at Mfamosin in Akamkpa LGA of Cross River State. The cement was procured in bags from different retail outlet sources. Calabar River sand was used as fine aggregate (FA) throughout the study. The crushed granite used as coarse aggregate (CA), was obtained from a quarry in Akamkpa LGA of Cross River State, Nigeria. The aggregates were prepared in accordance with the requirements of [7] and [6].

Concrete specimens were prepared in the Cross River University of Technology Materials Laboratory. Batching by weight was adopted in the study. Physical test conducted on the concrete includes; slump test for workability and compressive strength determinations. The various concrete mixtures adopted for evaluation are shown in Table 4. Eight concrete mixes after [11] were considered. The mixtures are adopted for concrete of structural purpose and general construction for medium and high slump range

Slump test for each mix were carried out in accordance with [5]. Concrete cubes of $150 \mathrm{~mm}$ by $150 \mathrm{~mm}$ were prepared in accordance with [2].The samples were cured in the laboratory in accordance with [4].

Table 4: Mix Proportion

\begin{tabular}{|c|c|c|c|c|c|c|c|}
\hline $\begin{array}{c}\text { Grade } \\
\mathrm{N} / \mathrm{mm}^{2}\end{array}$ & $\begin{array}{l}\text { Slump } \\
(\mathrm{mm})\end{array}$ & Mix ratio & $\begin{array}{l}\text { Water- } \\
\text { cement } \\
\text { ratio } \mathrm{w} / \mathrm{c}\end{array}$ & $\begin{array}{l}\text { Cement } \\
\left(\mathrm{Kg} / \mathrm{m}^{3}\right)\end{array}$ & $\begin{array}{c}\text { Water } \\
\left(\mathrm{Kg} / \mathrm{m}^{3}\right)\end{array}$ & $\begin{array}{c}\text { Fine } \\
\text { Aggregate } \\
\left(\mathrm{kg} / \mathrm{m}^{3}\right)\end{array}$ & $\begin{array}{c}\text { Coarse } \\
\text { Aggregate } \\
\left(\mathrm{kg} / \mathrm{m}^{3}\right)\end{array}$ \\
\hline \multirow{2}{*}{20} & $30-60$ & $1: 2.19: 2.68$ & 0.48 & 350 & 168 & 766 & 937 \\
\hline & $60-180$ & $1: 2.23: 2.62$ & 0.57 & 350 & 200 & 782 & 918 \\
\hline \multirow{2}{*}{25} & $30-60$ & $1: 1.90: 2.32$ & 0.46 & 400 & 184 & 761 & 929 \\
\hline & $60-180$ & $1: 1.95: 2.38$ & 0.55 & 400 & 220 & 780 & 952 \\
\hline \multirow{2}{*}{30} & $30-60$ & $1: 1.72: 2.1$ & 0.44 & 450 & 198 & 774 & 946 \\
\hline & $60-180$ & 1:73:2.11 & 0.50 & 450 & 225 & 778 & 949.5 \\
\hline \multirow{2}{*}{35} & $30-60$ & 1:1.49:1.89 & 0.44 & 500 & 220 & 743 & 907 \\
\hline & $60-180$ & $1: 1.51: 1.84$ & 0.48 & 500 & 225 & 755 & 920 \\
\hline
\end{tabular}


Compressive test for the specimens were conducted in accordance with [3] for 1, 3, 7, 14, 21, 28, and, 56 days. Three specimens were tested for each mixture and the average compressive strength was computed. These were then plotted against curing age.

\section{RESULTS AND DISCUSSION}

\subsection{Materials Characterization}

Table 5 shows the chemical composition of the UNICEM Type-I cement used for the study. The properties of cement used meets the specification for Ordinary Portland Cement (Type-I), [13].

Table 5: Composition of Cement used

\begin{tabular}{|l|l|l|l|l|l|l|l|}
\hline $\mathrm{CaO}$ & $\mathrm{SiO}$ & $\mathrm{Al}_{2}$ & $\mathrm{Fe}_{2}$ & $\mathrm{Mg}$ & $\mathrm{SO}$ & $\mathrm{K}_{2}$ & $\mathrm{Na}$ \\
\hline 64.34 & 20.79 & 4.51 & 2.64 & 1.66 & 1.48 & 1.26 & 0.18 \\
\hline
\end{tabular}

Table 6 shows the specific gravity test results for both the fine and coarse aggregates used. The sand had a specific gravity of 2.55 is uniformly graded with coefficient of uniformity ( $\mathrm{Cu}$ ) of 6.0 showing it is well graded sand. The particle size distribution curve of the fine aggregate is shown in the grading envelope of Figure 1. The sand fell within the specified grading envelop, as required by [11]. In addition to satisfying the grading envelope requirement, the specific gravity and the percentage passing sieve size $600 \mathrm{u} \mu \mathrm{m}$ were used in the mix design of the concrete mixes in accordance with the revised British standard of Mix Design Method, [13].

The grading curve of the coarse aggregate is presented in Figure 2. The aggregate is well graded with maximum size of $20 \mathrm{~mm}$ and specific gravity of 2.70 . The aggregates specific gravity was used in determining total aggregates content during mix design.

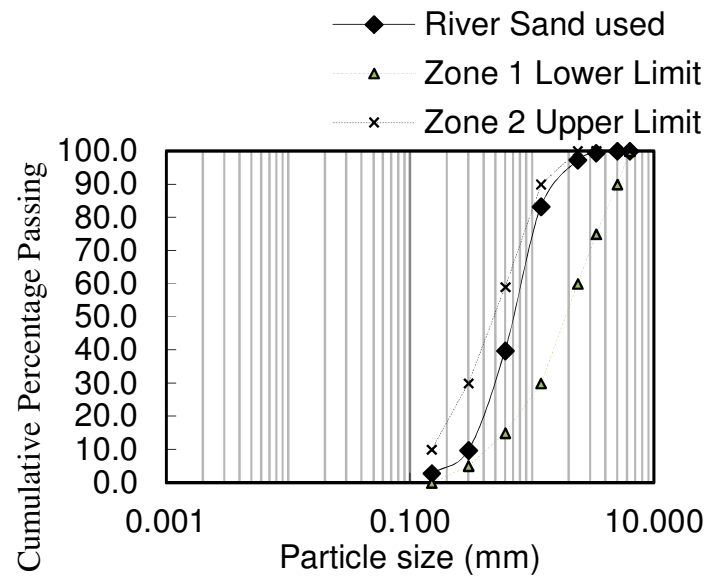

Figure 1: Particle Size Distribution of River sand used

\subsection{Workability of Concrete}

The results of the slump tests conducted on the different grades of concrete to measure concrete workability at various water cement ratios are summarized in Table 7 . The slump values for each mix fell within design range. Also, slump values for each grade increased with increased in the water cement ratio.

Table 6: Specific gravity test results for aggregates used

\begin{tabular}{|c|c|c|c|}
\hline $\mathrm{S} / \mathrm{N}$ & Description & $\begin{array}{c}\text { Fine } \\
\text { Aggregate }\end{array}$ & $\begin{array}{c}\text { Coarse } \\
\text { Aggregate } \\
\end{array}$ \\
\hline 1 & $\begin{array}{l}\text { Weight of empty bottle } \\
\left(\mathrm{M}_{1}\right)\end{array}$ & 475 & 475 \\
\hline 2 & $\begin{array}{l}\text { Weight of empty bottle }+ \\
\text { sample }\left(M_{2}\right)\end{array}$ & 950 & 1391 \\
\hline 3 & $\begin{array}{l}\text { Weight of empty bottle }+ \\
\text { sample }+ \text { water }\left(\mathrm{M}_{3}\right)\end{array}$ & 1565 & 2168 \\
\hline 4 & $\begin{array}{l}\text { Weight of bottle full of } \\
\text { water }\left(\mathrm{M}_{4}\right)\end{array}$ & 1276 & 1592 \\
\hline 5 & $\begin{array}{l}\text { Mass of Water Used }\left(\mathrm{M}_{3}-\right. \\
\left.\mathrm{M}_{2}\right)\end{array}$ & 615 & 1018 \\
\hline 6 & $\begin{array}{l}\text { Mass of Sample Used } \\
\left(\mathrm{M}_{2}-\mathrm{M}_{1}\right)\end{array}$ & 475 & 916 \\
\hline 7 & $\begin{array}{l}\text { Specific Gravity, GS = } \\
\frac{M_{2}-M_{1}}{\left(M_{4}-1\right)\left(M_{3}-M_{2}\right)}\end{array}$ & 2.55 & 2.70 \\
\hline
\end{tabular}

Table 7: Workability of Concrete Mixes

\begin{tabular}{llll}
\hline Grade & Mix ratio & w/c & Slump $(\mathrm{mm})$ \\
\hline \multirow{2}{*}{20} & $1: 2.19: 2.68$ & 0.48 & 47 \\
25 & $1: 2.23: 2.62$ & 0.57 & 62 \\
& $1: 1.90: 2.32$ & 0.46 & 51 \\
30 & $1: 1.95: 2.38$ & 0.55 & 156 \\
& $1: 1.72: 2.1$ & 0.44 & 39 \\
35 & $1: 73: 2.11$ & 0.50 & 101 \\
& $1: 1.49: 1.89$ & 0.44 & 46 \\
& $1: 1.51: 1.84$ & 0.48 & 100 \\
\hline
\end{tabular}

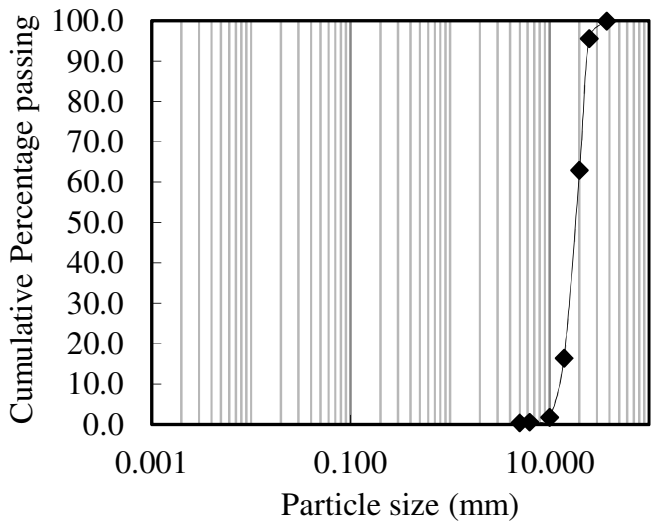

Figure 2: Particle size Distribution of coarse aggregate 


\subsection{Compressive strength of Concrete}

The plots of the compressive strength of concrete with age are presented in this section. As should be expected, strength of concrete increases with curing age, [13]. Mixes with lower water cement ratios showed higher strength than those with higher watercement ratios, [1], [13]. Cement gel are thought to be closer to one another with these mixes giving an early continuous gel system. With increase in water-cement ratio, workability increased at the detriment of the strength. Nonlinear regression analysis was performed on the experimental data set to produce Strength-Age (SA) curves. The SA curves produce are mixture specific, that is they serve as predicting curves for concrete satisfying similar water cement ratios, slump range and grade of concrete requirement.

Figure 3 through Figure 14 are the compressive strength plots of the grades of concrete under investigation. The concrete mixes are for medium and high slump range. Figures for combined water/cement ratios and slump range indicate that the mixes with lower water cement ratio had higher strength.

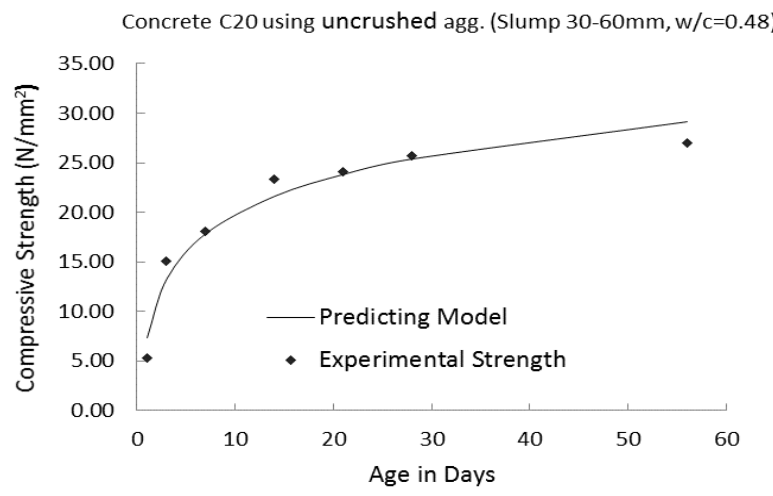

Figure 3: Strength-Age for concrete C20 (Slump30$60 \mathrm{~mm}$ )

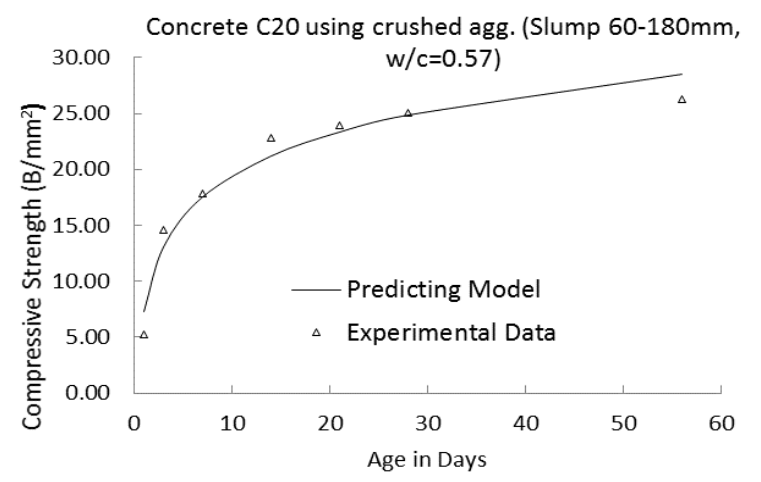

Figure 4: Strength-Age for concrete grade 20 (Slump60$180 \mathrm{~mm}$ ).

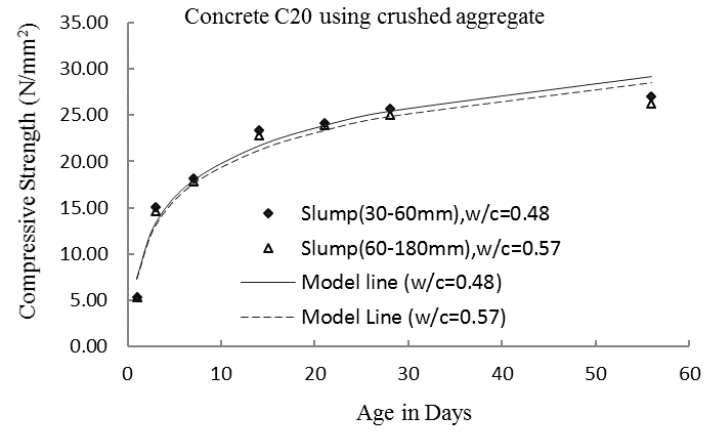

Figure 5: Combined Strength-Age for concrete C 20

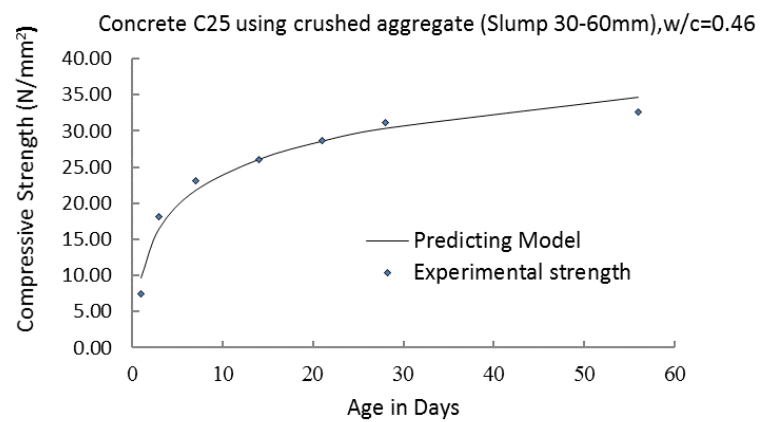

Figure 6: Strength-Age for concrete C25 (Slump30$60 \mathrm{~mm})$

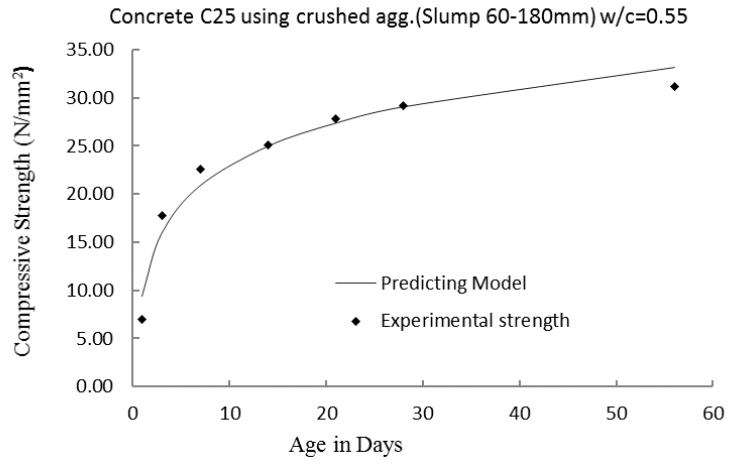

Figure 7: Strength-Age for concrete grade 25 (Slump60$180 \mathrm{~mm})$.

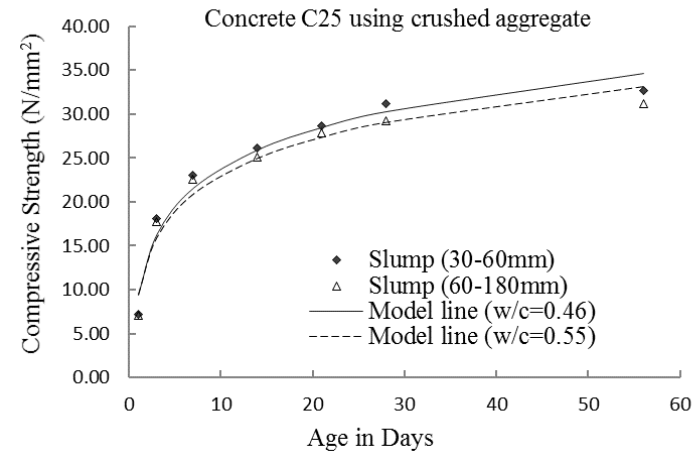

Figure 8: Combined Strength-Age for concrete C 25 


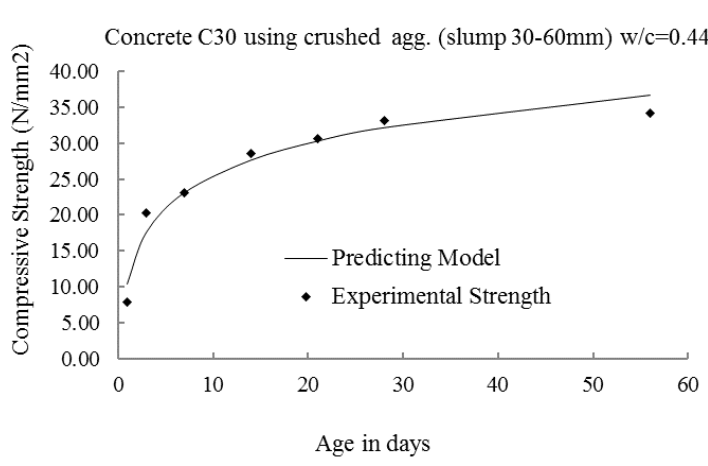

Figure 9: Strength-Age for concrete C30 (Slump30$60 \mathrm{~mm}$ )

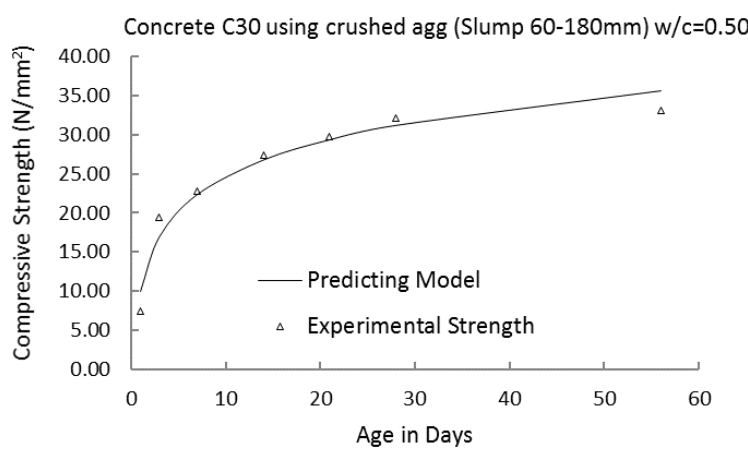

Figure 10: Strength-Age for concrete grade 25 (Slump60-180mm).

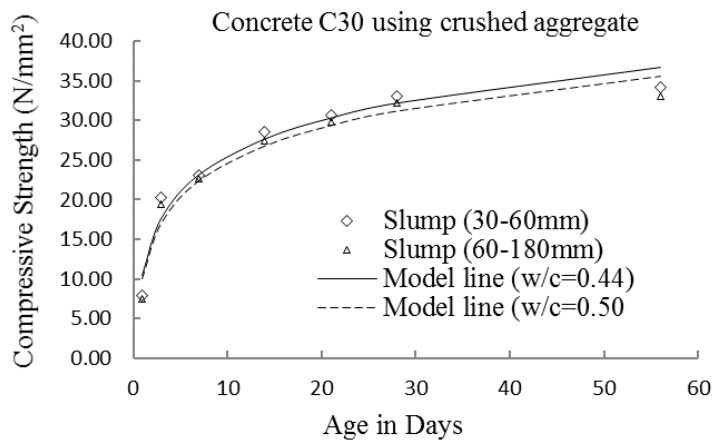

Figure11: Combined Strength-Age for concrete C 30

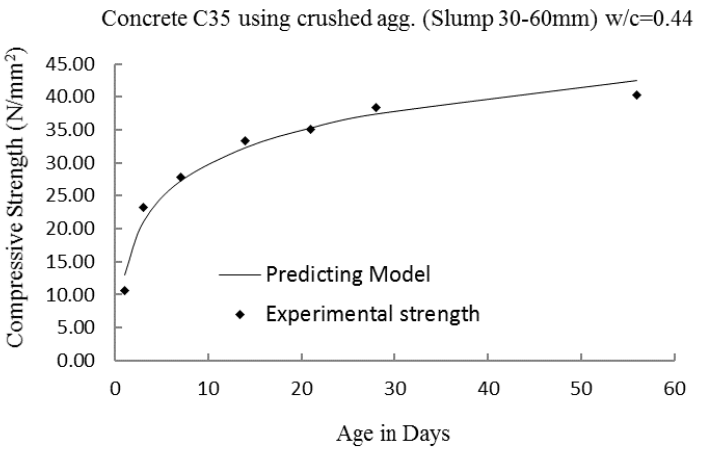

Figure 12: Strength-Age for concrete C35 (Slump30$60 \mathrm{~mm}$ )

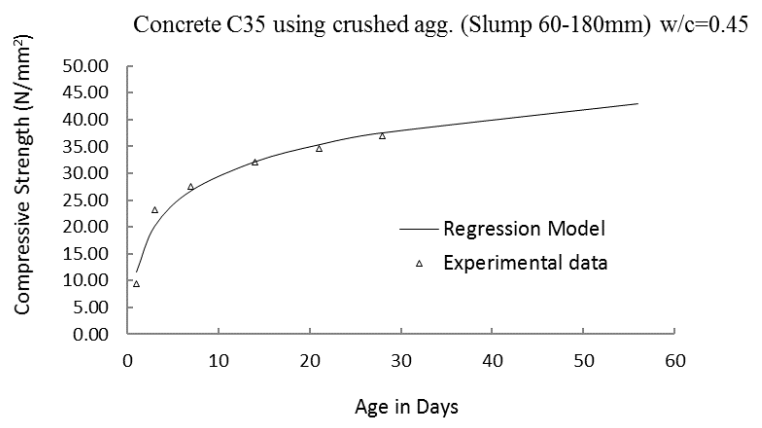

Figure 13: Strength-Age concrete grade 35 (Slump60$180 \mathrm{~mm})$.

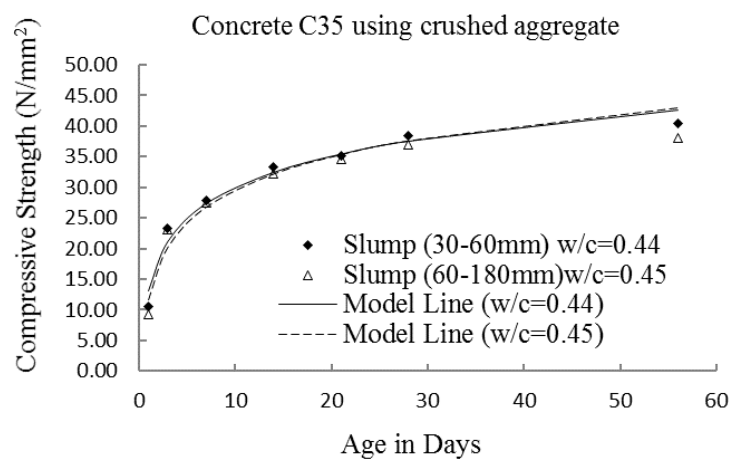

Figure14: Combined Strength-Age for concrete C 35

\subsection{Mixture Specific Duration-Strength models}

From the regression analyses, duration-strength models were developed for each mix of concrete under investigation. Equation (1) through(8)give models for predicting the time in hours for each concrete grade to achieve any particular strength with the given water cement ratio and slump range.

Concrete Grade 20 (C20):

$$
T=24 e^{\frac{(\sigma-7.3947)}{5.406}}
$$

For, $\mathrm{w} / \mathrm{c}=0.48$, Slump $=(30-60 \mathrm{~mm})$.

Where $\mathrm{T}$ is the age of concrete in hours., $\sigma$ is the compressive strength of concrete, $\mathrm{e}=2.718$.

$$
T=24 e^{\frac{(\sigma-7.2992)}{5.2659}}
$$

For, $\mathrm{w} / \mathrm{c}=0.57$, Slump $=(60-180 \mathrm{~mm})$.

Concrete Grade 25 (C25):

$$
T=24 e^{\frac{(\sigma-9.6001)}{6.2179}}
$$

For, $\mathrm{w} / \mathrm{c}=0.46$, Slump $=(30-60 \mathrm{~mm})$.

$$
T=24 e^{\frac{(\sigma-9.4317)}{5.8805}}
$$

For, $\mathrm{w} / \mathrm{c}=0.55$, Slump $=(60-180 \mathrm{~mm})$.

Concrete Grade 30 (C30):

$$
T=24 e^{\frac{(\sigma-10.42}{6.5148}}
$$

For, $\mathrm{w} / \mathrm{c}=0.44$, Slump $=(30-60 \mathrm{~mm})$.

$$
T=24 e^{\frac{(\sigma-9.9706)}{6.3557}}
$$


For, $\mathrm{w} / \mathrm{c}=0.50$, Slump $=(60-180 \mathrm{~mm})$.

Concrete Grade 35 (C35):

$$
T=24 e^{\frac{(\sigma-12.99}{7.3383}}
$$

For, $\mathrm{w} / \mathrm{c}=0.44$, Slump $=(30-60 \mathrm{~mm})$.

$$
T=24 e^{\frac{(\sigma-11.556}{7.8115}}
$$

For, $\mathrm{w} / \mathrm{c}=0.48$, Slump $=(60-180 \mathrm{~mm})$.

\subsection{Estimating Time for Striking Formwork/ Accommodation of Construction Loads.}

Table 7 presents estimated duration in hours for the attainment of desired compressive strength of concrete for the purpose of quick construction scheduling and sequencing. By the recommendations of BS8110, the minimum strength for soffit formwork of members in flexure to be removed is $10 \mathrm{~N} / \mathrm{mm}^{2}$. From the results of Table 7, it will take 38.86 hours for C20 concrete with lower cement ratio to achieve this minimum strength. Similarly, for the same C20 concrete with higher water cement ratio, the time to attain this minimum strength is 40.08 hours. In terms of grade of concrete, it will take 26.40 hours for C25 concrete to attain the minimum strength while C20 will take 38.86 hours, thus saving 12.46 hours when C25 is used. Higher grades of concrete therefore, require shorter time to strike off formwork.

The above estimated durations appears not feasible because the influence of the member sizes, span and type of formwork have not been accounted for. Let us assume the characteristic strength of concrete to be the criteria to strike off soffit formwork and remove props supporting members in flexure, from Table 7 , the time to attain the characteristic strengths for C20, C25, C30 and, C35 concrete are 247.04 hours (10.3 days), 285.57 hours (11.90 days), 484.54 hours (20.20 days), 481.58 hours (20.10 days) and, 267.72 hours (11.16 days), 338.74 hours (14.11 days), 560.67 hours (23.36 days), 482.49 hours (20.10 days) for medium and high slump range respectively. The characteristics strengths were attained in less than 28-day period recommended for props removal by [11].

\section{CONCLUSION}

The following conclusions were drawn from the study.

1. For the same grade of concrete, mixes with lower water-ratios take shorter duration to develop a desired strength.

2. Concrete with higher workability (higher slump values) take longer time to attain a given strength than those of lower workability (lower slump values).

3. Higher grades of concrete take shorter duration to achieve desired strength development.

4. Higher grade of concrete make for faster construction scheduling operations.

5. Construction scheduling and sequencing could be improved with the knowledge of 'what time' a given strength should be achieved for a mixturespecific concrete.

6. Developed models could be used to estimate stripping time, removal of props and accommodation of construction loads for members in flexure irrespective of size and type of formwork used.

\section{RECOMMENDATIONS}

1. The time to remove props or supports to concrete members in flexure should be based on when the designed characteristic strength has been achieved, this will make for faster construction scheduling operations.

2. Further studies on the effect of cement and aggregate type on the time to developed desired strength in concrete should be investigated.

3. The study recommends a review of Table II of the Nigerian General Specification for Roads and Bridges dealing with formwork minimum stripping time.

Table 8: Estimated Time for strength development (hours)

\begin{tabular}{ccccccccccc}
\hline \multirow{2}{*}{ Grade } & \multirow{2}{*}{ Slump (mm) } & \multirow{2}{*}{ w/c } & 7.5 & 10 & 15 & 20 & 25 & 30 & 35 & 40 \\
\hline \multirow{2}{*}{20} & $30-6 \mathrm{~mm}$ & 0.48 & 24.47 & 38.86 & 97.98 & 247.04 & 622.87 & - & - & - \\
& $60-180$ & 0.57 & 24.93 & 40.08 & 103.57 & 267.66 & 691.67 & - & - & - \\
\multirow{2}{*}{25} & $30-60 \mathrm{~mm}$ & 0.46 & 17.12 & 25.59 & 57.19 & 127.80 & 285.57 & 638.13 & - & - \\
& $60-180 \mathrm{~mm}$ & 0.55 & 17.28 & 26.43 & 61.86 & 144.76 & 338.74 & 792.67 & - & - \\
\multirow{3}{*}{30} & $30-60 \mathrm{~mm}$ & 0.44 & 15.33 & 22.50 & 48.47 & 104.42 & 224.93 & 484.54 & 1043.79 & - \\
& $60-180 \mathrm{~mm}$ & 0.50 & 16.27 & 24.11 & 52.95 & 116.27 & 255.32 & 560.67 & 1231.20 & - \\
& $30-60 \mathrm{~mm}$ & 0.44 & 11.36 & 15.97 & 31.56 & 62.38 & 123.29 & 243.66 & 481.58 & 951.81 \\
& $60-180 \mathrm{~mm}$ & 0.48 & 14.28 & 19.67 & 37.30 & 70.74 & 138.15 & 254.41 & 482.49 & 915.05 \\
\hline
\end{tabular}




\section{REFERENCES}

[1] Abolfazl, K. R, Peroti S. and Rahemi L 'The Effect of Water-Cement Ratio on Compressive and Abrasion Strength of the Nano Silica Concretes' World Applied Sciences Journal 17 (4), 2012, pp 540-545, ISSN 1818-4952.

[2] ASTM C31/C31M 'Practice for Making and Curing Concrete Test Specimens in the Field'. ASTM International, Pennsylvania, 2015.

[3] ASTM C39/C39M - 05'Standard Test Method for Compressive Strength of Cylindrical Concrete Specimens'. ASTM International, Pennsylvania, 2005.

[4] ASTM C-511: 'Specification for Moist Cabinets, Moist Rooms, and Water Storage Tanks Used in the Testing of Hydraulic Cements and Concretes'. ASTM International, Pennsylvania, 2013.

[5] ASTM C143/C143M-12: 'Standard Test Method for Slump of Hydraulic-Cement Concrete'. ASTM International, Pennsylvania, 2014.

[6] BS 812-105-2 'Testing Aggregate. Method for determination of particle size'. British Standards Institution, London, 1990.

[7] BS EN12620'Specification for aggregates from natural sources for concrete'. British Standards Institution, London, 2002.

[8] BS 8000-2.2, 'Workmanship on building sites. Code of practice for concrete work. Site work with in-situ and precast concrete'. British Standards Institution, London 1990.

[9] BS 8110 - Part 1: 'Structural use of concrete: Code of practice for design and Construction', Section 6.2.6.3 Striking of formwork. British Standards Institution London 1997.

[10] Clear, C. A. 'Formwork striking times for GGBS concrete: test \& site results' Proceedings of Institute of Civil Engineers, Structures and Buildings, November, 1994,pp 441-448.

[11] General Specifications for Roads and Bridges (1997), 'Government of the Federal Republic of Nigeria'.

[12] Harrison, T. A' Formwork Striking Times - Criteria, prediction and methods of assessment', CIRIA Report 136, 1995.

[13] Neville, A. M. (2011): 'Properties of Concrete'. Pearson Education Limited, Edinburgh Gate, England. 5th Edition, 2002, 304-305.

[14] Sadgrove, B. M. 'Freezing of concrete at an early age', Cement and Concrete Association, Technical Report 42, 1974, pg 503.

[15] L+C (Consulting Structural Engineers: 'Specification for Concrete' retrieved from ftp://ftp.bryenlangley.com/Christ_Church/Post Tender_Info/Engin eers_Drawings/Concrete\%20Specification.pdf accessed on $28^{\text {th }}$ July, 2015. 